\title{
Rotavirus and reovirus interaction with mouse peritoneal resident phagocytic cells
}

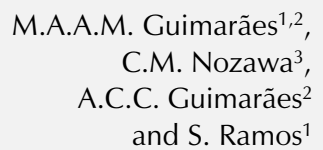

\author{
1Departamento de Virologia, Instituto de Microbiologia Professor Paulo de Góes, \\ Universidade Federal do Rio de Janeiro, Rio de Janeiro, RJ, Brasil \\ ${ }^{2}$ Serviço de Patologia Clínica, Laboratório de Virologia, Hospital Universitário \\ Clementino Fraga Filho, Universidade Federal do Rio de Janeiro, \\ Rio de Janeiro, RJ, Brasil \\ ${ }^{3}$ Departamento de Patologia Geral, Universidade Estadual de Londrina, \\ Londrina, PR, Brasil
}

\section{Correspondence}

M.A.A.M. Guimarães

Departamento de Virologia

Instituto de Microbiologia

Professor Paulo de Góes, UFRJ

21941-590 Rio de Janeiro, RJ

Brasil

Received November 12, 1996

Accepted August 27, 1997

\begin{abstract}
Rotaviruses and reoviruses are involved in human and animal diseases. It is known that both viruses penetrate the gastrointestinal tract but their interaction with phagocytic cells is unknown. To study this interaction, peritoneal resident phagocytic cells were used and rotavirus and reovirus replication in peritoneal phagocytic cells was observed. However, rotavirus replication in these cells led to the production of defective particles since MA-104 cells inoculated with rotavirus phagocytic cell lysate did not show any evidence of virus replication. On the basis of these results, we suggest that, although reovirus dissemination may be helped by these phagocytic cells, these cells may control rotavirus infection and probably contribute to the prevention of its dissemination.
\end{abstract}

Key words

- Rotavirus

- Reovirus

- Phagocytic cells
Rotavirus is a frequent cause of human and animal diarrhea worldwide. It is known that these viruses penetrate the gastrointestinal tract and replicate in enterocytes (absorptive cells) causing their destruction, sloughing and replacement by immature cells with reduced absorptive and digestive capacity, with the consequent occurrence of diarrhea. An important consequence for humans and animals is dehydration, which can be fatal if not treated.

Rotavirus infection seems to be limited to the gastrointestinal tract and, although some investigators mention the presence of viral antigens at other sites of the body (1-3), there is no convincing study demonstrating rotavirus dissemination after replication in enterocytes. Anatomopathological studies have demonstrated that the destruction of enterocytes by rotaviruses is self limited with complete recovery of villous epithelial morphology and function although the interaction between the virus and the host defense system is poorly understood.

It is known that specific antibodies are produced in response to rotavirus intestinal replication and also that after acute infection immunocompetent individuals show a good lymphoproliferative response to rotavirus antigens in vitro (4). There are few animal experiments studying host defense mechanisms against rotavirus. Some investigators describe the presence of rotavirus particles in phagocytes of the intestinal lamina pro- 
pria (5-7), but they did not indicate if these viruses are destroyed by these phagocytes.

Under natural circumstances reoviruses behave primarily as enteric viruses. Reovirus serotype 1 replicates in intestinal absorptive cells. Moreover, after oral inoculation, reovirus serotypes 1 and 3 adhere to the intestinal $M$ cells $(8,9)$ and are transported across these cells into the Peyer's patches. Infectious viruses are observed in mesenteric lymph nodes although their interaction with phagocytic cells has not been described (10).

The objective of the present study was to determine rotavirus and reovirus interaction with peritoneal resident phagocytic cells in vitro. Rotavirus was used as a model of localized infection limited to the gastrointestinal tract while reovirus was used as a model of systemic infection.

Peritoneal phagocytic cells were obtained from adult Swiss mice (40-45 days old) after peritoneal lavage with $10 \mathrm{ml}$ of growth medium (RPMI 1640 medium containing $1 \mathrm{M}$ HEPES, $100 \mathrm{IU} / \mathrm{ml}$ penicillin, $2.5 \mu \mathrm{g} / \mathrm{ml}$ gentamicin, and $2.5 \mu \mathrm{g} / \mathrm{ml}$ amphotericin B) supplemented with $20 \%$ fetal bovine serum. A cell suspension containing $10^{6}$ cells per $\mathrm{ml}$ of growth medium was distributed into Leighton tubes containing glass coverslips ( $2 \mathrm{ml}$ per tube) and incubated at $37^{\circ} \mathrm{C}$ for $1 \mathrm{~h}$. After incubation, the supernatant was discarded, and the cell culture was washed with RPMI medium and maintained in growth medium at $37^{\circ} \mathrm{C}$.

The peritoneal cells obtained were tested for phagocytic activity 24 and $48 \mathrm{~h}$ after harvesting. The cell monolayers were incubated with a $1 \%(\mathrm{w} / \mathrm{v})$ suspension of Saccharomyces cerevisiae for $60 \mathrm{~min}$ at $37^{\circ} \mathrm{C}$. After incubation the coverslips were washed and fixed for $10 \mathrm{~min}$ in methanol for subsequent staining with Giemsa. After staining the coverslips were mounted on slides with Canadian Balsam and observed by light microscopy.

For phagocytic cell inoculation simian rotavirus (strain SA-11) and reovirus serotype 1 were used, both adapted to MA-104 cells with a multiplicity of infection (MOI) of approximately 10 . The phagocytic cell cultures were inoculated in one experimental test $24 \mathrm{~h}$ after being obtained and $48 \mathrm{~h}$ later in the other experiment. An inoculum volume of $0.5 \mathrm{ml}$ per tube was used and the cells were incubated at $37^{\circ} \mathrm{C}$ for $2 \mathrm{~h}$ for virus

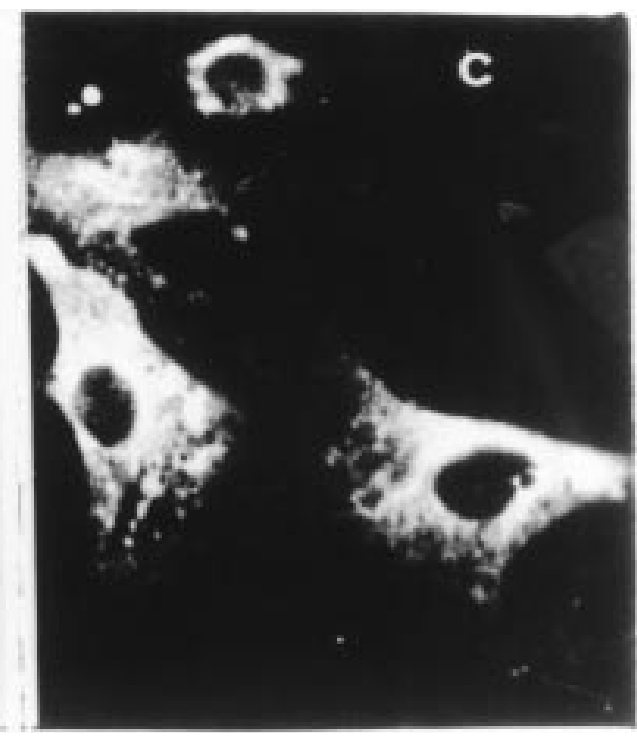

Figure 1 - Peritoneal phagocytic cells $(a, b)$ and MA-104 cells (c) inoculated with rotavirus (a) and reovirus (b,c), and processed by immunofluorescence. $a$ and $b, 400 X ; c, 160 X$. Characteristic perinuclear fluorescent staining of the infected cells can be observed. 
adsorption. After incubation the inoculum was discarded, the cells were washed twice and then maintained in growth medium (RPMI 1640 medium containing 1 M HEPES, $100 \mathrm{IU} / \mathrm{ml}$ penicillin, $2.5 \mu \mathrm{g} / \mathrm{ml}$ gentamicin, and $2.5 \mu \mathrm{g} / \mathrm{ml} \mathrm{amphotericin} \mathrm{B)} \mathrm{supplemented}$ with $2 \%$ fetal bovine serum.

Virus replication was detected by two different methods: the indirect immunofluorescence test (IF) using a specific immune serum (a rabbit anti-rotavirus and a rabbit anti-reovirus immune serum, prepared as described in Ref. 11) and a labeled fluorescein anti-rabbit immune serum (Pasteur).

The other form of viral replication detection in phagocytic cells was by inoculation of MA-104 cells with the lysate of the infected phagocytic cell. MA-104 cells grown on glass coverslips were inoculated $24 \mathrm{~h}$ after trypsinization with $0.5 \mathrm{ml}$ of the infected phagocytic cell lysate and incubated at $37^{\circ} \mathrm{C}$ for $2 \mathrm{~h}$ for viral adsorption. After incubation the inoculum was discarded and the monolayers were washed twice and maintained in MEM Eagle containing 1 M HEPES, $100 \mathrm{IU} / \mathrm{ml}$ penicillin, $2.5 \mu \mathrm{g} / \mathrm{ml}$ gentamicin, and $2.5 \mu \mathrm{g} / \mathrm{ml}$ amphotericin B, without bovine serum but supplemented with crystalline trypsin $(0.04 \mathrm{mg} / \mathrm{ml})$. Virus replication in the inoculated MA-104 cells was observed by microscopic visualization of suggestive viral cellular cytopathic effect (CPE) and by the observation of specific fluorescence.

In the present study, the peritoneal cells in culture showed the characteristics of phagocytic cells described by Carr (12). They were firmly attached to the glass surface of the coverslips, showed no replication in culture, depended on fetal bovine serum to survive, showed phagocytic activity and had a life time of about 7 days. After inoculation these phagocytic cell cultures showed signs of rotavirus and reovirus replication by IF (Figure 1a,b). The phagocytic cells inoculated with reovirus showed more than $90 \%$ of fluorescent cells while those inoculated with rotavirus showed fluorescence in less than $2 \%$ of the cells in culture. Different results were observed when MA-104 cells were inoculated with virus phagocytic cell lysate. MA-104 cells inoculated with rotavirus phagocytic cell lysate showed no signs of viral replication until the third passage of the lysate on these cells. Nevertheless, MA-104 cells inoculated with reovirus phagocytic cell lysate showed a characteristic CPE and the presence of cytoplasmic specific fluorescence by IF (Figure 1c).

Phagocytic cells are a group of heterogeneous cells with multiple functions. Some of these cells are located at the points of entry of the organism acting as a barrier against infectious agents, engulfing and generally destroying them. If viruses replicate in these cells, dissemination of the infection may occur since some of these cells migrate throughout the organism. In our experiments the presence of specific fluorescence in phagocytes inoculated with rotavirus and reovirus suggested an intrinsic susceptibility of these cells to both viruses. The replication of reovirus in macrophage cells and the production of infective particles that caused infection in MA-104 cell cultures are consistent with the pathogenicity of these viruses that disseminate throughout the body after penetrating the intestinal mucosa probably inside macrophage cells.

The demonstration of rotavirus replication in phagocytic cells agrees with reports by different investigators who described the presence of rotavirus particles in subepithelial phagocytic cells, suggesting that this may be a mechanism of virus interaction with the immune system $(5-7,13,14)$. The observation of rotavirus replication in phagocytic cells but the absence of viral replication in MA-104 cells inoculated with the lysate of these phagocytic cells suggests the production of defective viral particles. It is possible that, although the replication of rotavirus in phagocytic cells may occur, the production of defective particles could limit its dissemination throughout the body. These results 
concerning rotaviruses may explain the experimental findings of Eiden et al. (15) who observed that $\mathrm{T}$ lymphocyte-deprived mice did not produce specific antibodies after rotavirus intestinal replication but had the same disease course as control mice (immunocompetent mice). The destruction of rotavirus particles by the phagocytic cells or the production of defective particles by these cells may explain the benign course of the infection in the Tlymphocyte-deprived mice.

Studies on rotavirus replication in macrophage cells are in progress in our laboratory to understand the interaction of rotavirus with these cells.

\section{References}

1. Santoshan M, Yolken $H$, Quiroz E, Dillman L, Oro G, Reeves W \& Sack B (1983). Detection of rotavirus in respiratory secretions of children with pneumonia. Journal of Pediatrics, 103: 583-585.

2. Grunow JE, Dunton SF \& Joseph LW (1985). Human rotavirus-like particles in a hepatic abscess. Journal of Pediatrics, 106: 73-76.

3. Fragoso M (1986). Rotavirus in nasopharyngeal secretions of children with upper respiratory tract infection. Diagnostic Microbiology and Infectious Disease, 4: 8788.

4. Totterdell BM, Patel S, Banatvala JE \& Chrystie IL (1988). Development of a lymphocyte transformation assay for rotavirus in whole blood and breast milk. Journal of Medical Virology, 25: 27-36.

5. Stair EL, Mabus CA, Twiehaus MJ \& Underdahe NR (1973). Neonatal calf diarrhea: Electron microscopy of intestines infected with a reovirus-like agent. Veterinary Pathology, 10: 155-170.
6. Suzuki H \& Konno T (1975). Reovirus-like particles in jejunal mucosa of Japanese infant with acute infectious non-bacterial gastroenteritis. Tohoku Journal of Experimental Medicine, 115: 199-211.

7. Snodgrass DR, Madeley CR, Wells PW \& Angus KW (1977). Human rotavirus in lambs: Infection and passive protection. Infection and Immunity, 16: 268-270.

8. Wolf JL, Kauffman RS, Finberg R, Dambrauskas R \& Fields BN (1983). Determinants of reovirus interaction with the intestinal $\mathrm{M}$ cells and absorptive cells of murine intestine. Gastroenterology, 85: 291-300.

9. Wolf $\mathrm{JL}$, Rubin $\mathrm{DH}$, Finberg R, Kauffman RS, Sahrpe AH, Trier JS \& Fields BN (1981). Intestinal M cells: a pathway for entry of reovirus into the host. Science, 212: 471-472.

10. Kauffman RS, Wolf JL, Finberg R, Trier JS \& Fields BN (1983). The sigma 1 protein determines the extent of spread of reovirus from the gastrointestinal tract of mice. Virology, 124: 403-410.
11. Guimarães MAAM \& Nozawa C (1990) Acridine orange metachromasia in the cytoplasm of simian rotavirus (SA-11) infected MA-104 cell cultures. Brazilian Journal of Medical and Biological Research, 23: 169-177.

12. Carr I (1977). The Macrophage. 2nd edn. Academic Press, London, New York.

13. Mebus CA, Wyatt RG \& Kapikian AZ (1977). Intestinal lesions induced in gnotobiotic calves by the virus of human infantile gastroenteritis. Veterinary Pathology, 14: 273-282.

14. Guimarães MAAM, Chagas V, Nozawa CM, Takiya C, Maia PC \& Souza SO (1994). Experimental infection of newborn mice with EDIM rotavirus. Brazilian Journal of Medical and Biological Research, 27: 671-675.

15. Eiden J, Lederman HM, Voderfecht $\mathrm{S}$ \& Yolken $R$ (1986). T cell deficient mice display normal recovery from experimental rotavirus infection. Journal of Virology, 57: 706-708. 